\title{
Using noble gases to trace the origin and accumulation of Helium in Weiyuan gas field, Sichuan Basin
}

\author{
W. ZHONG ${ }^{1,3}$, S. QIN ${ }^{2}$, G. HOLLAND ${ }^{1}$, Z. ZHOU ${ }^{3}$ \\ ${ }^{1}$ Department of Earth and Environmental Sciences, University of \\ Manchester, UK (wanxu.zhong@postgrad.manchester.ac.uk) \\ ${ }^{2}$ Research Institute of Petroleum Exploration \& Development \\ (RIPED), PetroChina, China (qsf@petrochina.com.cn) \\ ${ }^{3}$ Lancaster Environment Centre, Lancaster University, UK \\ (z.zhou4@lancaster.ac.uk)
}

Sichuan Basin is a key area for helium exploration due to a large number of enriched $U$ and Th magmatic intrusions and granite basement. Furthermore, deep faults, large-scale marine sedimentary strata and anticline structures are common in the basin, which could provide favorable conditions for migration and localized accumulation of helium. Weiyuan gas field is located in Leishan-Longnvsi paleo-uplift in the southwest Sichuan Basin. Reservoirs are developed in Sinian, Cambrian and Ordovician marine strata. The Weiyuan gas field is the first and only area developed for economic helium production in the Sichuan Basin. Therefore, understanding the origin and accumulation processes of helium in the Weiyuan area is critical for evaluating the potential of helium resources in the Sichuan Basin.

In this study 7 gas samples are collected from the wellheads of production wells drilled into Sinian, Cambrian and Ordovician strata. ${ }^{4} \mathrm{He}$ concentrations range from $7.57 \times 10^{-4}$ to $9.84 \times 10^{-4}$ $\mathrm{cm}^{3} \mathrm{STP} / \mathrm{cm}^{3}$. The ${ }^{4} \mathrm{He}$ concentration in the Sinian strata is higher than that in the Cambrian and Ordovician strata. ${ }^{3} \mathrm{He} /{ }^{4} \mathrm{He}$ ranges from $0.03 \mathrm{R}_{\mathrm{a}}$ to $0.07 \mathrm{R}_{\mathrm{a}}$, which suggests a strong crustal-radiogenic signature. ${ }^{4} \mathrm{He} /{ }^{20} \mathrm{Ne}$ is significantly higher than atmospheric value of 0.288 , indicating that the atmospheric $\mathrm{He}$ is negligible. Therefore, the ${ }^{4} \mathrm{He}$ in all the samples is predominately derived from the crust. ${ }^{20} \mathrm{Ne} /{ }^{36} \mathrm{Ar}$ ranges from 0.0816 to $0.320 .{ }^{84} \mathrm{Kr} /{ }^{36} \mathrm{Ar}$ varies from 0.0123 to $0.062 .{ }^{130} \mathrm{Xe} /{ }^{\beta 6} \mathrm{Ar}$ is between $2.71 \times 10^{-4}$ and $7.73 \times 10^{-4}$.

The fractionation pattern observed in atmosphere-derived noble gases cannot be explained by gas-water fractionation models. Equilibration of water with oil present in the Weiyuan gas field can increase ${ }^{20} \mathrm{Ne} /{ }^{36} \mathrm{Ar}$ and decrease ${ }^{84} \mathrm{Kr} /{ }^{36} \mathrm{Ar}$ and ${ }^{130} \mathrm{Xe} /{ }^{36} \mathrm{Ar}$ of gas from the water. Therefore, oil-water fractionation models may explain the observed fractionation pattern. The accumulation of helium in the Weiyuan gas field can be attributed to radiogenic origin in the local granite followed by migration to trap. Groundwater played a significant role in the preservation of helium in Weiyuan gas field, Sichuan Basin. 